\title{
Listening to Patients: How Understanding Health Information Use Can Contribute to Health Literacy Constructs
}

\author{
Maria Souden, Moderator/Organizer \\ University of Michigan School of Information \\ 1075 Beal Ave. \\ Ann Arbor, MI 48109-2112 \\ seramar@umich.edu
}

\author{
Ellen L. Rubenstein, Organizer \\ Graduate School of Library \& Information Science \\ University of Illinois, Urbana-Champaign \\ 501 E. Daniel St., Champaign, IL 61820 \\ erubens3@illinois.edu
}

\section{Information Use Track \\ Endorsed for SIG-HEALTH sponsorship and requesting SIG-USE co-sponsorship.}

(additional panelists listed below)

\begin{abstract}
This panel focuses on expanding concepts of health literacy by exploring how the acquisition and use of health information through the context of people's daily lives significantly enhances their understanding and implementation of both acute and chronic health treatment and management. Prevalent health literacy initiatives emphasize core information literacy skills and concerns by addressing issues such as readability, clarity in communication, and appropriate vetting of online health information sources; however, these measures do not address the intricate ways in which people interact with and use information when making decisions about their health.
\end{abstract}

In this session, researchers working within a variety of cross-disciplinary arenas and contexts, including information science, communications, nursing, medicine, health services, and public health, will engage with the question of how information behavior-based studies can impart additional dimensions to an understanding of health literacy beyond basic literacy skills and information delivery. We argue that information behavior perspectives can enrich the conceptual base of health literacy, contributing a deeper understanding of people's engagement with and use of health information in the context of their lived experience with health conditions.

The six panelists will provide insight into additional dimensions of experience relevant to health literacy,

ASIST 2010, October 22-27, 2010, Pittsburgh, PA, USA.

Copyright 2010 Maria Souden and Ellen L. Rubenstein

Permission to make digital or hard copies of all or part of this work for personal or classroom use is granted without fee provided that copies are not made or distributed for profit or commercial advantage and that copies bear this notice and the full citation on the first page. To copy otherwise, or republish, to post on servers or to redistribute to lists, requires prior specific permission and/or a fee. including how people identify and understand their information needs, how interpersonal sources are considered as health information, the value of experiencebased or peer information, and how engagement in online communities, families, and social networks contributes to how health information is experienced, considered, evaluated, used, and applied in negotiating health and illness.

\section{KEYWORDS}

Health information, health literacy, health information literacy, everyday life information use, information behavior, consumer health informatics.

\section{INTRODUCTION}

The sheer volume of available health information and pressures from a fragmented and constrained healthcare system require increased patient involvement in treatment and care decisions (Eng, 1998; Lewis, Chang, \& Friedman, 2005), driving health information seeking and elevating the importance of information in dealing with health problems and conditions. Individuals are faced with both initiating and increasing their own efforts to become informed participants in the health care process (Johnson, 2003) as well as interpreting their encounters with medical professionals within the context of their everyday life experiences.

The ubiquity and widespread use of health information has raised concerns about health literacy and the ways in which people process and understand health information (Baker, 2006). Health literacy constructs tend to focus on individual capacity for processing information (e.g., reading level and prior knowledge) and the characteristics of the information itself (e.g., reading level, "living room" language). Within this context health information literacy has emerged as a set of professional practices that consider and ameliorate these factors, prescribing a role for information professionals as 
intermediaries charged with connecting people to authoritative information sources (MLA, 2010).

Dervin (2005), however, describes numerous additional challenges in bridging the health literacy gap, including top-down transmission procedures based on faulty assumptions about the user, ignoring the experiential realities of people's lives and assuming they are ignorant about information; decreasing trust in expert and institutional resources; the complexity of the health information environment; and the lack of contextually situated information interactions. For people experiencing illness or a health concern, formalized interactions with information or healthcare systems may represent only a fraction of their information experience-information seeking and use is likely to take place in more diverse and multifaceted ways connected to the context of their daily lives.

Information behavior studies have focused on understanding people and their needs in the broader context of their experience, not just in relationship to their use of information systems or resources (cf. Dervin \& Nilan, 1986; Wilson, 1994). Information behavior perspectives on information use have the potential to broaden notions of health literacy beyond the point of information delivery, considering how information is actually used and made valuable in people's lives and made sense of in the context of their own experiences. Recent work focusing on the use of information in coping with and managing illness emphasizes affective, sociocultural, and collaborative aspects of the illness context as an influence on health information management (Brashers, Goldsmith, \& Hsieh, 2002); the role of uncertainty and communication in illnessrelated information seeking and use (Hogan \& Brashers, 2009); information work as deliberate action shaped by the shifting demands of ongoing illness (Hogan \& Palmer, 2005); and the value of peer-based health information exchange (Veinot, under review).

In recasting and reformulating some of the basic underpinnings of health literacy, some questions to consider include:

- What constitutes a source of health information in the lived experience of illness?

- What does the idea of "quality health information" mean given varied intentions that people with illness often have when they approach a source?

- To what extent do models of information seeking translate to the lived experience of illness?

The panelists will each spend 10 minutes presenting their own research related to various aspects of health information use (as described below) and reflect on how these perspectives could potentially inform our ideas about what constitutes health literacy. They will then engage in discussion with the moderator and audience to explore ways to reformulate current paradigms. Audience members should leave the panel session with an expanded perspective on the ways that information science theory and research can contribute to and broaden health literacy constructs.

\section{PANELISTS and THEIR PERSPECTIVES}

Maria Souden, MSI (moderator), is a PhD Candidate at the University of Michigan School of Information. The recipient of a Beta Phi Mu Eugene Garfield Doctoral Dissertation Fellowship, Souden was also acknowledged by ASIST in 2008 when her submission, Information Work in the Chronic Illness Experience, was selected as the SIGUSE Best Information Behavior Poster. Her research interests include information behavior; health information seeking, provision, and use in personal and organizational contexts; information in the chronic illness experience; information, communication, and learning; and community information and engagement.

Souden's dissertation research, The Information Experiences of People with Chronic Illness as Shaped by Daily Life and Healthcare Contexts, which placed second in the ALISE 2010 Doctoral Student Poster Competition, is a multi-level analysis that looks at the roles and meanings of information in dealing with chronic illness from a patient-centered perspective and examines how the patient experience of information is shaped by the healthcare context. Chronic conditions are managed by people in the midst of their everyday lives on multiple levels of experience. Yet information is often delivered through a bio-medically focused healthcare system organized to provide acute care. Souden's portion of the presentation will provide the conceptual framework for the panel and use examples from her own research to highlight how consideration of the disconnect between patient and provider perspectives on information could contribute to a reshaping of health literacy constructs.

Dale Brashers, PhD, is the David L. Swanson Professorial Scholar and Head of the Department of Communication and Professor of Medicine at the University of Illinois in Urbana-Champaign. He currently is vice-chair of the Health Communication Division of the International Communication Association (ICA). He has received the Golden Anniversary Monograph Award and the Health Communication Division Outstanding Article Award from the National Communication Association, and the ICA Young Scholar Award. His research has been funded by the National Institutes of Health, including the National Institute of Nursing Research (NINR) and the National Institute of Mental Health (NIMH).

Brashers recently completed a NINR-funded project on uncertainty management for people living with HIV. That study included a test of a peer support intervention designed 
to teach communication skills to people who were newly diagnosed with HIV. The underlying principle of the intervention was that providing people communications skills to facilitate seeking and managing information is more efficacious than simply providing information about an illness. His part of the panel discussion will focus on uncertainty and information management in the context of health literacy and the contribution of underlying communication skills such as self-disclosure and support seeking.

Shelagh K. Genuis, MLIS, is an Interdisciplinary PhD Candidate with the School of Library and Information Studies and the Faculty of Nursing at the University of Alberta. The 2010 recipient of the Medical Library Association's Thomson Reuters/MLA Doctoral Fellowship, her research interests include information behavior, particularly with respect to health information; knowledge translation in health fields; information literacy; and information retrieval. Her dissertation, Making Sense of Evolving Health Information: Navigating Uncertainty in Everyday Life, explores how women in the menopause transition, respond to, make sense of, and use (or do not use) evolving health information, and how health professionals perceive their roles and act as information providers within this context.

While much has been written about the instrumental challenges of health information literacy, little attention has been paid to the incomplete, emergent nature of health evidence and to the challenge that evolving health information presents not only to professionals, but to individuals seeking to make sense of and use health information within an everyday life context. In this context individuals are commonly assimilating and responding to information from both formal and informal sources, including health professionals, media and internet, and inter-personal relationships. Genuis' presentation focuses on the critical influence of intra-personal information sources, and the profound impact of social positioning on women's engagement with and use of health information.

Timothy P. Hogan, PhD, is research health scientist at the Center for Management of Complex Chronic Care, one of 14 Centers of Excellence funded by the Health Services Research and Development Service (HSR\&D) of the United States Department of Veterans Affairs (VA), and research assistant professor in the Program in Health Services Research, Stritch School of Medicine, Loyola University Chicago. Hogan's research focuses on individuals with complex, chronic healthcare needs and how they access and use different kinds of health information over the trajectory of disease management.

Hogan is currently principal investigator on two HSR\&Dfunded studies, one focused on use of VA's personal health record (PHR) among veterans with spinal cord injuries, and the other focused on health information management among veterans with co-morbid chronic conditions. He serves on two national committees that advise the VA Office of Health Information on research issues related to VA's PHR. He is also the recipient of the 2006 Thomson Scientific and Medical Library Association Doctoral Fellowship Award, and the 2008 Berner-Nash Memorial Award for outstanding doctoral dissertation in the Graduate School of Library and Information Science, University of Illinois at Urbana-Champaign.

Hogan's contribution to the discussion will explore multimorbidity as a complicating factor in chronic disease management, corresponding conceptual implications for existing models of health information seeking/behavior, and how the development of constructs that better account for the ongoing management of multiple health conditions can strengthen health literacy promotion efforts.

Ellen L. Rubenstein, MLS, is a PhD Candidate at the Graduate School of Library and Information Science at the University of Illinois, Urbana-Champaign. Her poster, Dimensions of Information Exchange in an Online Breast Cancer Support Group, was selected as a Certificate of Merit winner in the ASIS\&T 2009 SIG-USE Best Information Poster Competition, and she received a 2010 Beta Phi $\mathrm{Mu}$ Eugene Garfield Dissertation Fellowship for her dissertation, An Ethnography of an Online Breast Cancer Support Group. Her research interests include health information access and use, information seeking in a variety of contexts, online communities, social capital, social networks, and ethnography.

Encompassing these various interests, Rubenstein's dissertation is An Ethnography of an Online Breast Cancer Support Group, which examines information exchange, communication, and community in a particular online space. Within this community, health information is acquired through purposeful, directed conversations as well as through casual interactions, which then are processed and translated into various uses and actions. Her part of the discussion will consider the interplay of conversation, information acquisition, and information use as they manifest in the daily interactions of online community participants.

Tiffany C.E. Veinot, MLS, PhD, is Assistant Professor in the School of Information and the School of Public Health at the University of Michigan. Veinot's research focuses on health information behavior within marginalized communities and families; relationships between health information technologies and the social organization of health care; and social network-based information systems/services for health consumers and patients.

Veinot is Proceedings Chair of the ACM International Conference on Health Informatics and a member of the Biomedical Library and Informatics Review Committee of 
the National Library of Medicine at the National Institutes of Health. She has held or co-held grants from the Centers for Disease Control and Prevention, Michigan Institute on Clinical and Health Research and the Canadian Institutes for Health Research. She also held a three-year doctoral fellowship from the Social Sciences and Humanities Research Council. Veinot's publications have been honored by ASIS\&T SIG-USE, ALISE and CAIS.

Some of Veinot's current projects include a study of the role of information in family-level coping, support and care in relation to chronic illness; a study of peer-based information exchange in renal dialysis clinics; an investigation into patient-provider information exchange in diabetes care, and testing an online social network intervention for HIV/STI prevention. Her presentation will focus on how a better understanding of collaborative information seeking and use among patients, their peers, and their families can lend nuance to the concept of health literacy as a social construct rather than solely an individual one.

\section{In Memoriam}

This panel is dedicated to our collaborator, Dr. Dale Brashers (1960-2010). A highly regarded health communications scholar whose work informed and enriched information behavior, Dale was thrilled at the prospect of presenting his work at ASIS\&T this year and his ideas will certainly be present at this panel. Their formative role in our vision for the topic is inextricable. It is in this spirit that we retain his contribution to this paper and endeavor to represent his work in the conference session.

\section{REFERENCES}

Baker, D. (2006). The meaning and measure of health literacy. Journal of General Internal Medicine, 21(8), 878-883.

Brashers, D. E., Goldsmith, D. J., \& Hsieh, E. (2002). Information Seeking and Avoiding in Health Contexts. Human Communication Research, 28(2), 258-271.
Dervin, B. (2005). Libraries reaching out with health information to vulnerable populations: Guidance from research on information seeking and use. [Lit Review]. Journal of the Medical Library Association, 93(4), S74S80.

Dervin, B., \& Nilan, M. (1986). Information needs and uses. Annual Review of Information Science and Technology(21), 3-33.

Eng, T. R., Maxfield, A., Patrick, K., Deering, M. J., Ratzan, S. C., \& Gustafson, D. H. (1998). Access to Health Information and Support: A Public Highway or a Private Road? JAMA, 280(15), 1371-1375.

Hogan, T. P., \& Brashers, D. E. (2009). The theory of communication and uncertainty management: Implications from the wider realm of information behavior. In T. D. Afifi \& W. A. Afifi (Eds.), Uncertainty, Information Management, and Disclosure Decisions: Theories and Applications (pp. 45-66). New York: Routledge.

Hogan, T. P., \& Palmer, C. L. (2005, October 28 November 2, 2005). "Information Work" and Chronic Illness: Interpreting Results from a Nationwide Survey of People Living with HIV/AIDS. Proceedings of the American Society for Information Science and Technology (ASIS\&T) Annual Meeting, Charlotte, NC

Johnson, J. D. (2003). On contexts of information seeking. Information Processing \& Management, 39(5), 735-760.

Lewis, D., Chang, B. L., \& Friedman, C. P. (2005). Consumer health informatics. In D. Lewis, G. Eysenbach, R. Kukafka, P. Z. Stavri \& H. B. Jimison (Eds.), Consumer Health Informatics : Informing Consumers znd Improving Health Care (pp. 1-7). New York: Springer.

MLA (2010, 3/10/2010). Medical Library Association Resources: Health Information Literacy Retrieved 30 March, 2010, from http://www.mlanet.org/resources/.

Veinot, T.C. (under review) "We have a lot of information to share with each other": Understanding the Value of Peer-Based Health Information Exchange. Information Research.

Wilson, T. D. (1994). Information needs and uses: Fifty years of progress? In B. C. Vickery (Ed.), Fifty Years of Information Progress : A Journal of Documentation Review (pp. 15-51). London: Aslib. 